\title{
Computed tomographic findings and treatment of a bull with pituitary gland abscess
}

\author{
Ueli Braun ${ }^{1 *} \mathbb{D}$, Alexandra Malbon², Manon Kochan ${ }^{1}$, Barbara Riond ${ }^{1}$, Fredi Janett ${ }^{1}$, Cornelia Iten ${ }^{4}$ \\ and Matthias Dennler ${ }^{3}$
}

\begin{abstract}
Background: In cattle, the prognosis of brain abscess is unfavourable and treatment is therefore not recommended. To the knowledge of the authors, there has been no report of successful treatment of a brain abscess in cattle.This report describes the clinical, computed tomographic and postmortem findings in a Holstein-Friesian bull with a hypophyseal abscess.
\end{abstract}

Case report: The main clinical findings were generalised ataxia, ptyalism, prolapse of the tongue, dropped jaw, dysphagia, head tilt and unilateral ptosis. Cerebrospinal fluid evaluation revealed 2437 leukocytes/ $\mu$ and severe pleocytosis. CT examination of the head showed a cavitary lesion consistent with an abscess in the hypophysis. Treatment consisted of gentamicin and flunixin meglumine for 3 days and amoxicillin for 40 days. The neurological signs resolved within 8 days of the start of treatment. The bull was slaughtered 11 months later because of infertility, and a postmortem examination was carried out. Histologically, a mild chronic non suppurative meningoencephalitis restricted to the ventral diencephalon was diagnosed. In addition, there was mild to moderate multifocal chronic lymphoplasmacytic hypophysitis with mild multifocal fibrosis.

Conclusions: This case report stresses the significance of $\mathrm{CT}$ in confirming the clinical and laboratory diagnosis of central nervous system disorders in cattle and for localising brain lesions. Treatment of the brain abscess resulted, with respect to the central nervous disorder, in a successful outcome and was encouraging considering that most cases have an unfavourable prognosis.

Keywords: Bovine, Brain, Pituitary, Abscess, Computed tomography, Therapy

\section{Background}

Brain abscesses are relatively rare in cattle, but when present the most common location is in the brainstem [1]; other parts of the brain are only occasionally affected. One of the most common bacterial causes of brain abscess is Trueperella pyogenes. In calves, Fusobacterium necrophorum may ascend from the oral cavity to the brain, resulting in abscess formation. Other bacteria occasionally isolated include Actinomyces bovis and Mycobacterium bovis [2]. Bacteria usually gain access

\footnotetext{
*Correspondence: ubraun@vetclinics.uzh.ch

${ }^{1}$ Department of Farm Animals, Vetsuisse Faculty, University of Zurich, Zurich, Switzerland

Full list of author information is available at the end of the article
}

to the brain via the bloodstream. Brain infection also may result from oropharyngeal infection with Listeria monocytogenes, which ascends the trigeminal nerve in ruminants [2], and from complications associated with dehorning and otitis media [2]. Extension of nasopharyngeal infection after insertion of a nose ring [3] and suppurative encephalitis after a perforating skull fracture [4] also have also been reported. The pituitary region of ruminants is a preferential location for brain abscesses. The pituitary gland is surrounded by the rete mirabile, an extensive capillary network, which predisposes the region to bacterial colonisation [2]. The principal clinical signs of pituitary abscess are difficulty prehending and chewing food, dysphagia, excessive salivation, tongue 
flaccidity and mandibular weakness. Some animals have bradycardia. A tentative diagnosis of brain abscess is based on the clinical signs and may be aided by the results of cerebrospinal fluid (CSF) analysis, although focal suppurative brain lesions are not always accompanied by pleocytosis and increased protein concentration in the CSF. Computed tomography (CT) and magnetic resonance imaging (MRI) have been used successfully for diagnosing brain abscesses in cattle [5, 6]. MRI was used to diagnose a brainstem abscess in a 3-month-old calf [7], and $\mathrm{CT}$ was used to image brain abscesses in two calves [6] and a cerebellar abscess in another calf [5].

The prognosis of brain abscess usually is unfavourable $[1,2]$. Antibiotics and nonsteroidal anti-inflammatory drugs do not have an appreciable effect on brain abscesses and therefore treatment is usually not recommended. Surgical excision combined with antibiotic treatment is considered the treatment of choice in human patients with pituitary abscess [8-11] but successful treatment with antibiotics alone also has been reported [12]. This case report describes the clinical signs, treatment and postmortem findings in a Holstein-Friesian bull with an abscess in the hypophysis confirmed using CT. The bull was treated successfully, but was slaughtered 11 months later because of poor semen quality.

\section{Case presentation}

A 22-month-old bull was referred to the Department of Farm Animals, University of Zurich, because of pyrexia. Bronchopneumonia caused by $T$. pyogenes was diagnosed based on the results of clinical, radiographic and ultrasonographic examinations and bacterial culture of tracheal secretions. The bull was treated with amoxicillin $\left(7 \mathrm{mg} / \mathrm{kg}\right.$ intramuscularly; Clamoxyl ${ }^{\circledR}$, Zoetis Switzerland, Zürich) for 12 days. The bull responded to treatment and was healthy at the time of discharge. The bull was referred again 24 days after the end of the antibiotic treatment because of recurrence of fever in addition to neurological deficits.

At the second referral, the bull was severely obtunded and had low head carriage, poor appetite, decreased rectal temperature $\left(38.2{ }^{\circ} \mathrm{C}\right)$, severe bradycardia [32 beats/ min (bpm)] and a normal respiratory rate without any signs of respiratory disease. Neurological examination showed generalised ataxia, hypersalivation, mild prolapse of the tongue, dropped jaw, dysphagia, mild head tilt to the right and ptosis on the right side.

Haematological analysis showed increased total protein concentration in plasma $(90 \mathrm{~g} / \mathrm{l}$, reference range $60-80 \mathrm{~g} / \mathrm{l})$ and clot formation in the glutaraldehyde test after $4 \mathrm{~min}$ (reference range 10-15 $\mathrm{min}$ ). The $\mathrm{pH}$ of a venous blood sample was slightly decreased at 7.37 (reference range 7.40-7.50). All other measured variables (white blood cell count; concentrations of fibrinogen, urea, bilirubin and electrolytes; enzyme activities) were within the reference ranges. CSF collected at the atlantooccipital foramen under ultrasonographic guidance [13] was colourless, slightly turbid and had a markedly increased leukocyte count of 2437 cells/ $\mu$ l (reference range $<10 \mathrm{cells} / \mu \mathrm{l})$. Cell differentiation showed severe mixed pleocytosis with 59\% neutrophils, 26\% lymphocytes, 9\% eosinophils and 6\% monocytes (Fig. 1). The protein concentration in the CSF was markedly increased at $3.1 \mathrm{~g} / \mathrm{l}$ (reference range $<0.75 \mathrm{~g} / \mathrm{l})$ [14].

A CT examination (Siemens Somatom Sensation Open) was carried out with the bull under general anaesthesia in dorsal recumbency with the following scan parameters: slice thickness $1.5 \mathrm{~mm}, \mathrm{kVP} 140, \mathrm{~mA} \mathrm{370}$, rotation time $1 \mathrm{~s}$, collimator pitch 0.75 with a field of view of $410 \times 410 \mathrm{~mm}$. The images were reconstructed in a soft tissue and bone algorithm with a matrix of $512 \times 512$. The hypophysis had a higher pre-contrast attenuation value than the surrounding brain tissue (Fig. 2) and measured $3.1 \times 4.8 \times 4.5 \mathrm{~cm}$ (height, width, length). The gland occupied the entire sella turcica. The attenuation value was slightly lower on the left side of the hypophysis (left: $75.6 \pm 17 \mathrm{HU}$; right: $94.2 \pm 16 \mathrm{HU}$ ). The CT scan was repeated with the same scan parameters $100 \mathrm{~s}$ after intravenous injection (flow rate: $2.5 \mathrm{ml} / \mathrm{s}$ ) of $600 \mathrm{ml}$ of iohexol, a non-iodic contrast medium (Accupaque $250^{\circledR}$ ) and showed that the attenuation value of the right side of the hypophysis was increased to $108.1 \pm 19 \mathrm{HU}$ (Fig. 3). There was an irregularly shaped cavern characterised by low attenuation $(77 \pm 16 \mathrm{HU})$ at the centre of the right half of the hypophysis. A radiographic diagnosis of a cavitary lesion at the centre of the right side of the hypophysis was made. The most likely aetiology of the lesion was

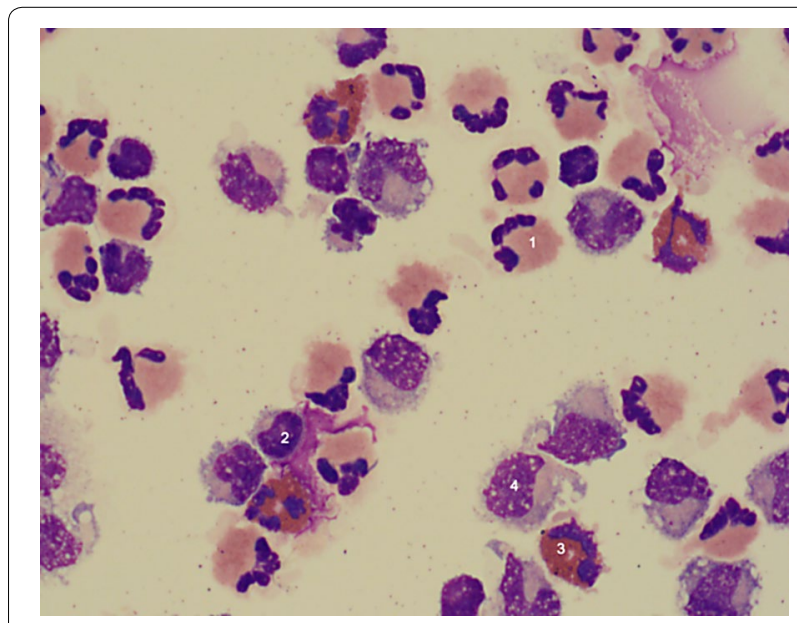

Fig. 1 Cerebrospinal fluid. Cytological smear of cerebrospinal fluid from a Holstein-Friesian bull with abscess of the diencephalon. There is severe mixed-cell pleocytosis with neutrophils (1), lymphocytes (2), eosinophils (3) and monocytes (4) 
an abscess. Differential diagnoses of the cavitary lesion including a Rathke's cleft cyst, haematoma or neoplasm were considered less likely because of the asymmetry of the lesion, the pre-contrast attenuation values and the clinical findings.

Based on all the findings, a focal lesion in the right rostrodorsal aspect of the hypophysis, was diagnosed. The results of CSF analysis indicated severe suppurative inflammation and combined with CT findings allowed the diagnosis of an abscess. Even though the prognosis was guarded, the bull underwent treatment because of his high genetic merit. The bull was treated with gentamicin $\left(4 \mathrm{mg} / \mathrm{kg}\right.$; Vetagent ${ }^{\circledR}$, MSD Animal Health, Lucerne), flunixin meglumine $\left(0.75 \mathrm{mg} / \mathrm{kg}\right.$; Fluniximin ${ }^{\circledR}$, Graeub, Berne) administered intravenously for three days, $10 \mathrm{l}$ /day of a solution containing 50 glucose and $9 \mathrm{~g}$ $\mathrm{NaCl} / \mathrm{l}$ administered via an indwelling catheter for four days and amoxicillin $\left(7 \mathrm{mg} / \mathrm{kg}\right.$; Clamoxyl $\left.{ }^{\circledR}\right)$ administered intramuscularly for 40 days. The neurological signs, particularly the dropped lower jaw, protruding tongue and slow jaw movements, remained unchanged for several days but then subsided gradually and resolved by day 9 of treatment. Thereafter, the health status and appetite were normal and the rectal temperature remained in the reference range $\left(38.4-38.9{ }^{\circ} \mathrm{C}\right)$. The heart rate increased to $60 \mathrm{bpm}$ within three days of treatment and was in the reference range (60-66 bpm) on 18 days of the 35-day hospitalisation period. Furthermore, because both testicles decreased in size, testosterone concentration was measured and a semen analysis carried out. The testosterone concentration in serum was decreased at $0.28 \mathrm{ng} /$ $\mathrm{ml}$ (reference range $0.4-3.0 \mathrm{ng} / \mathrm{ml}$ ) and the bull had severe teratozoospermia. The bull remained otherwise healthy and was discharged 35 days after the start of treatment. Eleven months later, the bull was slaughtered because of continued poor semen quality, and the brain, internal organs and testes were examined post mortem.

The pituitary gland weighed $3 \mathrm{~g}$ and appeared relatively small but had no other gross abnormalities. The brain, including the hypophysis, the testes, and their accessory glands were fixed in $10 \%$ neutral buffered formalin, processed by routine methods for histology, sectioned at $2 \mu \mathrm{m}$, and stained with haematoxylin and eosin (H\&E). Histologic examination of the diencephalon on the left side of the midline showed multifocal perivascular lymphocytic and plasma cell cuffing of small vessels, which was seen predominantly within peripheral white matter tracts of the ventral diencephalon. The cuffs formed single-cell to two-cell layers in the Virchow-Robin spaces (Fig. 4). Capillaries in the adjacent grey matter also were frequently associated with small numbers of lymphocytes and plasma cells. There was no neuronal damage. There was mild perivascular cuffing in the ventral white matter of the diencephalon to the right of the midline.

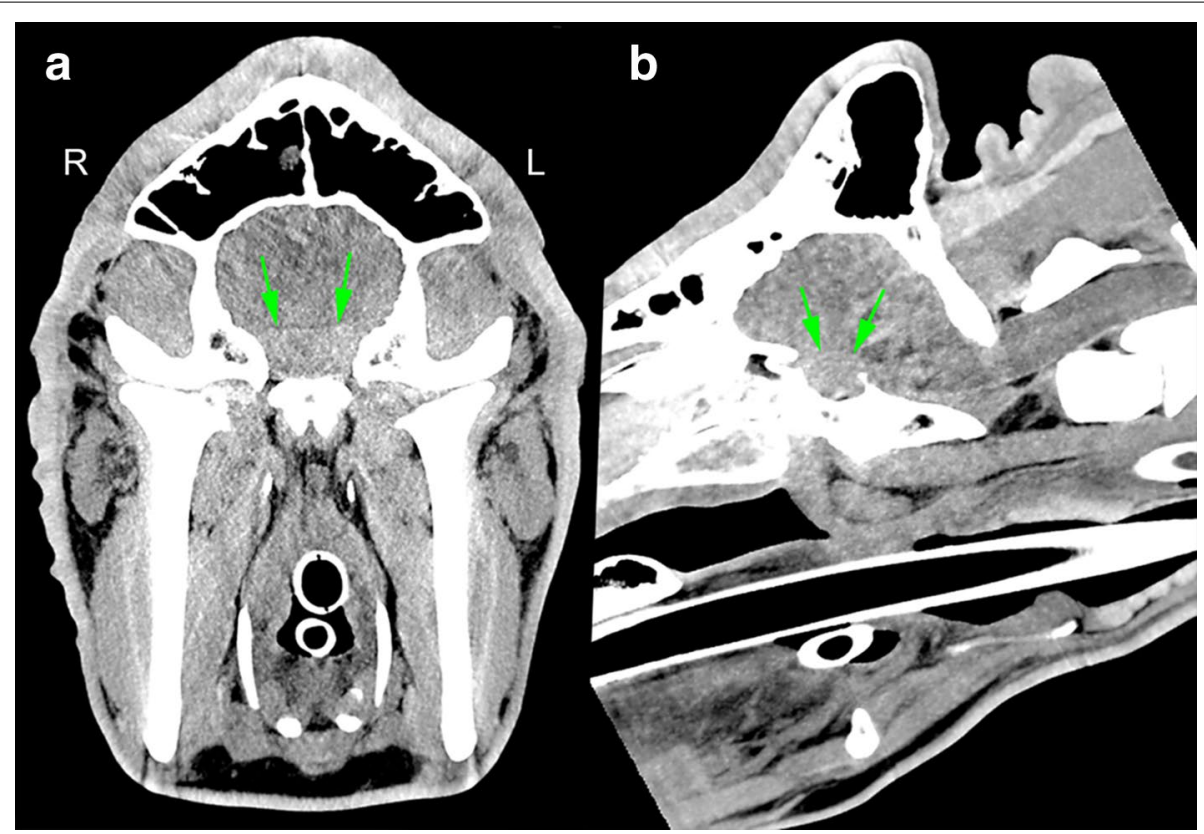

Fig. 2 Pre-contrast CT image. Transverse $\mathbf{a}$ and sagittal b pre-contrast CT image reconstruction in a soft tissue algorithm (window level 50, window width 200) of the brain of a Holstein-Friesian bull with abscess of the hypophysis. The hypophysis (green arrows) had a heterogeneous attenuation pattern and a higher attenuation value than the surrounding brain parenchyma. The attenuation value was slightly lower on the left side of the hypophysis than on the right side 


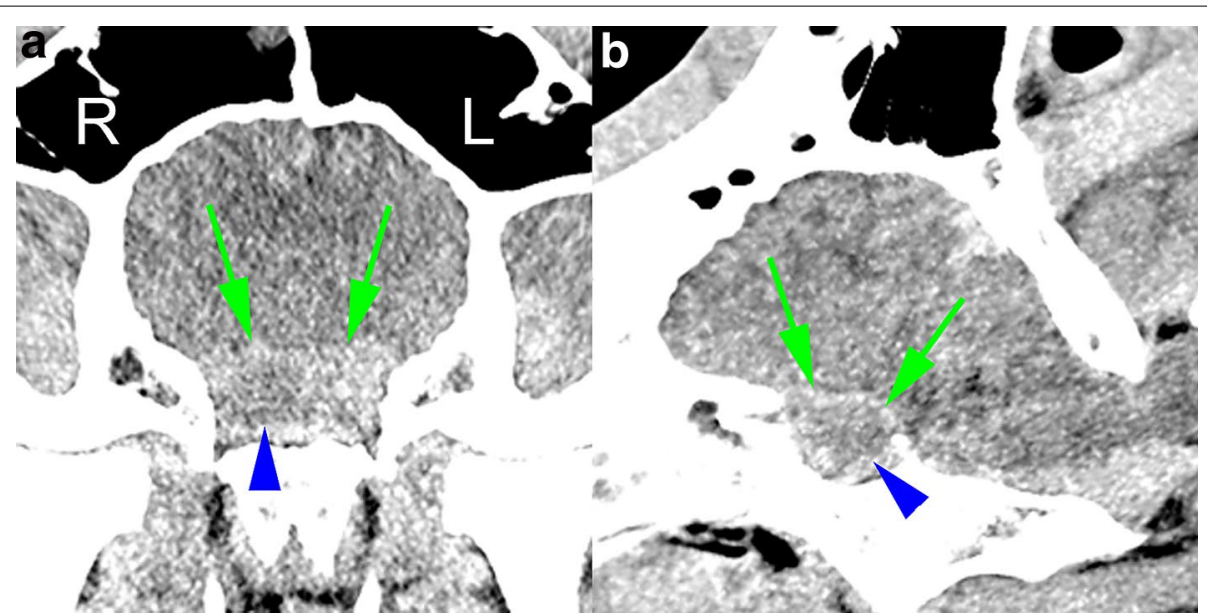

Fig. 3 Contrast-enhanced CT image. Transverse $\mathbf{a}$ and sagittal $\mathbf{b}$ contrast-enhanced CT image reconstruction in a soft tissue algorithm (window level 50, window width 200) of the brain of a Holstein-Friesian bull with abscess of the hypophysis. The attenuation value of the hypophysis (green arrows) was higher than in the pre-contrast image. There is a cavity at the centre of the right side of the hypophysis with low attenuation (blue arrow heads). An abscess in the hypophyseal tissue is the most likely diagnosis of this cavitary lesion, whereas a Rathke's cleft cyst or neoplasm is less likely

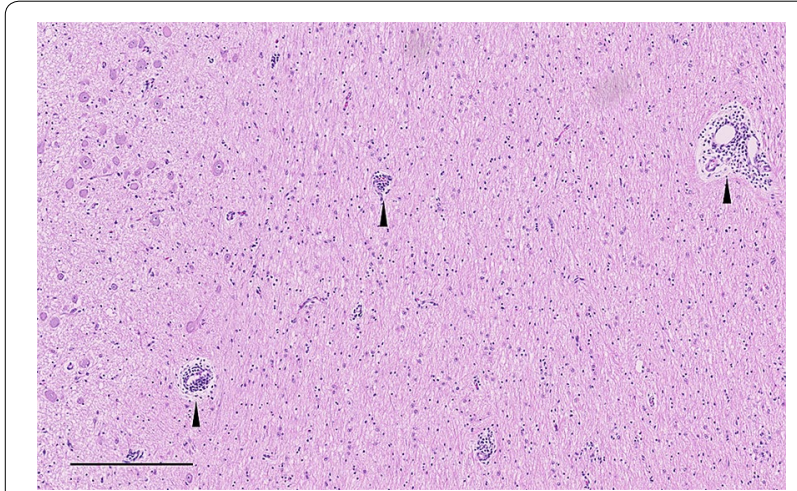

Fig. 4 Photomicrograph of the diencephalon. Cross section through the diencephalon to the left of the midline showing mild nonsuppurative perivascular cuffing of small vessels (arrow heads). H\&E, bar $200 \mu \mathrm{m}$

Occasional extravascular lymphocytes and plasma cells were present in the ventral meninges. Anastomosing thin branches of fibrous tissue were seen between acini in the pars distalis of the pituitary gland, and moderate numbers of lymphocytes and plasma cells were present dorsally toward the pars intermedia. There was mild to moderate multifocal infiltration of lymphocytes and plasma cells in the pars intermedia. The pars nervosa and to a lesser extent the infundibulum had multifocal individual and follicular aggregates of lymphocytes and smaller numbers of plasma cells (Fig. 5). Immunohistochemical staining for CD3 (T cells) and CD20 (B cells) (CD3: mouse monoclonal antibody, Dako M7254; CD20: rabbit polyclonal antibody, RB-9013-P, Thermo

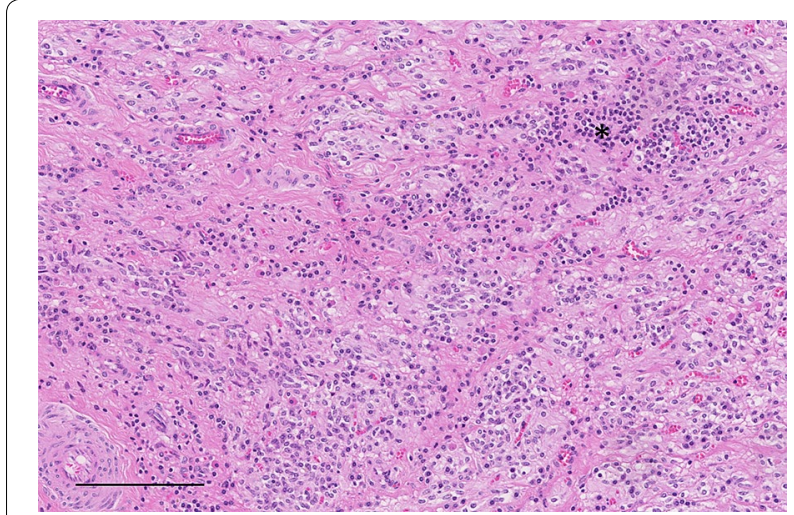

Fig. 5 Photomicrograph of the pituitary gland. Longitudinal section through the pituitary gland at the level of the junction between the pars nervosa and pars intermedia. This junction is vague and there are diffuse lymphocytes and plasma cells. One aggregate is marked with an asterisk. H\&E, bar $100 \mu \mathrm{m}$

Fisher Scientific, Reinach) showed a mixed population of stained cells and revealed numerous scattered lymphocytes, which were not clearly evident with H\&E staining, in the pars distalis. Discrete focal increases in glial cell density with an asymmetric distribution were seen in the medulla oblongata on both sides of the midline. The histological diagnosis of mild chronic non-suppurative meningoencephalitis that appeared to be restricted to the ventral diencephalon was established. Additionally there was mild to moderate multifocal chronic lymphoplasmacytic hypophysitis with mild multifocal fibrosis.

The testes were symmetrical and each measured $13 \times 7 \times 4 \mathrm{~cm}$. The left and right testes weighed 296 and 
288 g (reference: $267.5 \pm 14.4 \mathrm{~g}$ [15]), respectively. The seminiferous tubules of both testes contained small numbers of spermatogenic cells of varying and disordered stages of development with occasional multinucleated and degenerated cells suggesting impaired spermatogenesis (Fig. 6). There were no histological signs of orchitis, epididymitis or inflammation of the accessory glands.

The neurological signs described in this case report were typical of those described for cattle with pituitary abscess [1] and pointed to the involvement of several cranial nerves that arise from the medulla oblongata. Flaccidity of the tongue was attributable to hypoglossal nerve paralysis, dropped jaw to trigeminal nerve paralysis, dysphagia and salivation to glossopharyngeal and vagal nerve paralysis, head tilt to the right to vestibular nerve paralysis and unilateral ptosis to facial nerve paralysis. Lateralisation of some of the nerve deficits suggested a lesion on the right side of the brain.

The severe bradycardia (32 bpm) was of particular interest. Bradycardia is a common finding in bovine spongiform encephalopathy even though affected cows exhibit signs of extreme nervousness and apprehension [16]. This is thought to be due to pathological changes in the nuclei of the vagus nerve in the medulla oblongata, which controls cardiovascular parameters, resulting in vagotonic bradycardia. It is possible that a similar mechanism caused bradycardia in the present case. Lateralisation of clinical signs is typical of listeriosis but also can be caused by abscesses and tumours. Cytological examination of CSF revealed severe purulent inflammation and thus was not indicative of listeriosis, which is characterised by an increase in mononuclear cells in the CSF [17].

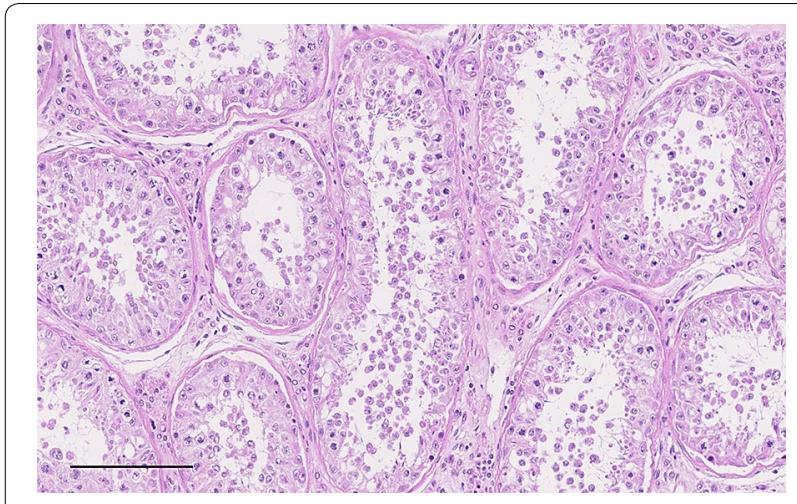

Fig. 6 Photomicrograph showing testicular atrophy. Seminiferous tubules of a Holstein-Friesian bull with testicular atrophy attributable to abscess of the hypophysis. The tubules contain exfoliated germ cells and normal spermatozoa are not observed; the majority of cells exhibit spermatogenic arrest prior to the differentiation stage of development (spermiogenesis) H\&E, bar $100 \mu \mathrm{m}$
CT images showed a focal lesion in the diencephalon which, aided by the CSF analysis, was interpreted as an abscess in the ventral diencephalon, immediately rostral and dorsal to the hypophysis. To the knowledge of the authors, this is the first CT characterisation of an abscess in the diencephalon in cattle. Because of the genetic value of the bull, treatment with amoxicillin, gentamicin and flunixin meglumine was started despite the unfavourable prognosis. This treatment regime has been used successfully at the Department of Farm Animals, University of Zurich, for more than 15 years for the treatment of cattle with listeriosis. The response of the bull to treatment with resolution of clinical signs after 9 days and discharge from the clinic after 35 days was surprising considering that brain abscess in cattle almost always has a poor prognosis. However, it can be assumed that the prognosis depends on a multitude of factors including the size of the abscess, thickness of the abscess wall, type of incriminating bacteria and anatomical location. However, the bull became infertile, which was likely related to decreased luteinizing hormone secretion and testosterone levels caused by inflammatory changes in the diencephalon. This was supported by the finding of abnormal spermiogenesis rather than inflammatory changes in the semen. In human medicine, persistent hypophyseal dysfunction also is a problem after treatment of a pituitary abscess [12] and affected patients may require pituitary hormone replacement therapy. The most likely aetiology of the abscess in the diencephalon was haematogenous spread of bacteria from bronchopneumonia, which preceded the neurological changes. Bacteria crossing the blood-brain barrier may colonize the CSF. The anatomy of the rete mirabilis and its intimate association with the pituitary gland may explain the predilection for pituitary abscesses in cattle [18]. The findings of mild, chronic, non-suppurative meningoencephalitis and mild to moderate hypophysitis do not conflict with the clinical, CSF or CT findings because successful treatment of the bull preceded the post-mortem examination by a year, during which time the bull was clinically healthy.

\section{Conclusions}

This case report stresses the significance of $\mathrm{CT}$ in the diagnosis of central nervous system disorders in cattle. The clinical, laboratory and radiographic diagnoses were supplemented by exact anatomical definition of the lesion. However, $\mathrm{CT}$ is an expensive technique limited to cases of special interest. This case showed that medical treatment of brain abscess in cattle can be successful.

\section{Authors' contributions}

UB prepared the manuscript, UB, MK, FJ and Cl examined and treated the bull, CT was performed by MD, and postmortem examination by AM. All authors read and approved the final manuscript. 


\section{Author details}

${ }^{1}$ Department of Farm Animals, Vetsuisse Faculty, University of Zurich, Zurich, Switzerland. ${ }^{2}$ Institute of Veterinary Pathology, Vetsuisse Faculty, University of Zurich, Zurich, Switzerland. ${ }^{3}$ Clinic of Diagnostic Imaging, Vetsuisse Faculty, University of Zurich, Zurich, Switzerland. ${ }^{4}$ Swissgenetics, Mülligen, Switzerland.

\section{Acknowledgements}

The authors thank the technicians of the Medical Laboratory for the haematological and biochemical analyses, the technical staff of the Institute of Veterinary Pathology for preparation of histological sections and the clinicians and agricultural technicians for the care and treatment of the bull.

\section{Competing interests}

The authors declare that they have no competing interests.

Received: 19 June 2016 Accepted: 4 January 2017

Published online: 13 January 2017

\section{References}

1. Stöber M. Infektionsbedingte Krankheiten der Organe des zentralen Nervensystems. In: Dirksen G, Gründer HD, Stöber M, editors. Innere Medizin und Chirurgie des Rindes. Berlin: Parey Buchverlag; 2002. p. 1051-78.

2. Radostits OM, Gay CC, Hinchliff KW, Constable PD. Brain abscess. In: Radostits OM, Gay CC, Hinchliff KW, Constable PD, editors. Veterinary Medicine. A Textbook of the Diseases of Cattle, Horses, Sheep, Pigs, and Goats. Philadelphia: Saunders Elsevier; 2007. p. 606-7.

3. Perdrizet JA, Dinsmore P. Pituitary abscess syndrome. Compend Contin Educ Pract Vet. 1986;8:S311-8

4. Braun U, Schweizer G, Pospischil A. Klinische Befunde bei vier Rindern mit offener Gehirnverletzung. Tierärztl Prax. 2003;31:183-6.

5. Lee KJ, Kishimoto M, Shimizu J, Kobayashi Y, Matsumoto K, Sasaki N, et al. Use of contrast-enhanced CT in the diagnosis of abscesses in cattle. J Vet Med Sci. 2011;73:113-5.
6. Lee K, Yamada K, Tsuneda R, Kishimoto M, Shimizu J, Kobayashi Y, et al. Clinical experience of using multidetector-row CT for the diagnosis of disorders in cattle. Vet Rec. 2009;165:559-62.

7. Tsuka T, Taura Y. Abscess of bovine brain stem diagnosed by contrast MRI examinations. J Vet Med Sci. 1999;61:425-7.

8. Vates GE, Berger MS, Wilson CB. Diagnosis and management of pituitary abscess: a review of twenty-four cases. J Neurosurg. 2001;95:233-41.

9. Dutta P, Bhansali A, Singh P, Kotwal N, Pathak A, Kumar Y. Pituitary abscess: report of four cases and review of literature. Pituitary. 2006;9:267-73.

10. Ciappetta P, Calace A, D'Urso PI, De Candia N. Endoscopic treatment of pituitary abscess: two case reports and literature review. Neurosurg Rev. 2008;31:237-46.

11. Dalan R, Leow MK. Pituitary abscess: our experience with a case and a review of the literature. Pituitary. 2008;11:299-306.

12. Zhu H, Gu XM, Hong J, Shen FX. Successful treatment of pituitary abscess with intravenous antibiotics: a case report and literature review. Genet Mol Res. 2014;13:10523-8.

13. Braun U, Attiger J, Brammertz C. Ultrasonographic examination of the spinal cord and collection of cerebrospinal fluid from the atlanto-occipital space in cattle. BMC Vet Res. 2015;11:227.

14. Mayhew J. Ancillary diagnostic aids. In: Mayhew A, editor. Large Animal Neurology. Oxford: Wiley-Blackwell; 2009. p. 47-61.

15. Harstine BR, Maquivar M, Helser LA, Utt MD, Premanandan C, DeJarnette $J M$, et al. Effects of dietary energy on sexual maturation and sperm production in Holstein bulls. J Anim Sci. 2015;93:2759-66.

16. Braun U. Klinische Symptome und Diagnose von BSE. Schweiz Arch Tierheilk. 2002;144:645-52.

17. Schweizer G, Ehrensperger F, Torgerson PR, Braun U. Clinical findings and treatment of 94 cattle presumptively diagnosed with listeriosis. Vet Rec. 2006;158:588-92.

18. Lorenz MD, Kornegay JN. Systemic or multifocal signs. In: Lorenz MD, Kornegay JN, editors. Handbook of Veterinary Neurology. St.Louis: Saunders; 2004. p. 355-416.

\section{Submit your next manuscript to BioMed Central and we will help you at every step:}

- We accept pre-submission inquiries

- Our selector tool helps you to find the most relevant journal

- We provide round the clock customer support

- Convenient online submission

- Thorough peer review

- Inclusion in PubMed and all major indexing services

- Maximum visibility for your research

Submit your manuscript at www.biomedcentral.com/submit
O Biomed Central 